\title{
Research Strategies in Science-based Start-ups Effects on Performance in Danish and Swedish Biotechnology
}

\author{
Valentin, Finn; Dahlgren, Johan Henrich; Lund Jensen, Rasmus
}

Document Version

Final published version

Publication date:

2006

\section{License \\ CC BY-NC-ND}

Citation for published version (APA):

Valentin, F., Dahlgren, J. H., \& Lund Jensen, R. (2006). Research Strategies in Science-based Start-ups: Effects on Performance in Danish and Swedish Biotechnology. DRUID - Danish Research Unit for Industrial Dynamics.

Link to publication in CBS Research Portal

\section{General rights}

Copyright and moral rights for the publications made accessible in the public portal are retained by the authors and/or other copyright owners and it is a condition of accessing publications that users recognise and abide by the legal requirements associated with these rights.

Take down policy

If you believe that this document breaches copyright please contact us (research.lib@cbs.dk) providing details, and we will remove access to the work immediately and investigate your claim. 


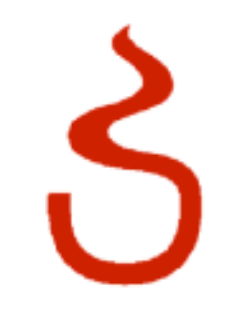

D R U 1 D

DRUID Working Paper No. 06-11

Research Strategies in Science-based Start-ups Effects on Performance in Danish and Swedish Biotechnology

By

Finn Valentin, Henrich Dahlgren and Rasmus Lund Jensen 


\title{
3
}

D R U 1 D

\section{Research Strategies in Science-based Start-ups Effects on Performance in Danish and Swedish Biotechnology}

\author{
Finn Valentin* \\ Copenhagen Business School \\ Department of Industrial Economics and Strategy \\ Kilevej 14a, 3th floor, DK - 2000 Frederiksberg \\ Tel.: +45 38152551 \\ Fax:+45 38152540 \\ E-mail: valentin@cbs.dk \\ Henrich Dahlgren \\ Copenhagen Business School \\ Department of Industrial Economics and Strategy \\ Research Centre on Biotech Business \\ Kilevej 14A, 3th floor, DK-2000 Frederiksberg \\ Tel.: +45 38152560 \\ Fax:+45 38152540 \\ E-mail: hd.ivs@cbs.dk \\ Rasmus Lund Jensen \\ Copenhagen Business School \\ Department of Industrial Economics and Strategy \\ Kilevej 14a, 3th floor, DK - 2000 Frederiksberg \\ Tel.: +45 38152539 \\ Fax:+45 38152540 \\ E-mail: rlj.ivs@cbs.dk \\ *) Corresponding author
}

\begin{abstract}
:
Although biotech start-ups fail or succeed based on their research few attempts have been made to examine if and how they strategize in this core of their activity. Popular views on Dedicated Biotech Firms (DBFs) see the inherent uncertainty of research as defying notions of strategizing, directing instead the attention to the quality of their science, or the roles of boards, management, and collaborative networks etc.

Using a unique comprehensive dataset on Danish and Swedish biotech start-ups in drug discovery this paper analyzes their research strategies. Adopting a Simonean point of departure we develop a contingency view on complex problem solving which structures the argument into three steps:

1) Characterising the problem architectures addressed by different types of DBFs;
\end{abstract}

April 6, 2006 


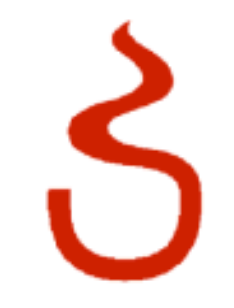

D R U 1 D

2) Testing and confirming that DBFs form requisite research strategies, by which we refer to problem solving approaches developed as congruent responses to problem architectures;

3) Testing and confirming that financial valuation of firms is driven by achievements conforming to requisite research strategies. These strategies, in turn, require careful combination of multiple dimensions of research.

Findings demonstrate that Shonhoovens classical argument that "strategy matters" is valid not only for the larger high-tech firms covered by her study, but also for small research-based start-ups operating at the very well springs of knowledge where science directly interacts with technologies. Even though a lot more research is needed along these lines, these findings offer new implications for the understanding, management, and financing of these firms.

Key words: Biotechnology, research strategy, discovery fields, valuation, performance measures JEL Codes: L25, L65, O32

ISBN 87-7873-202-6 


\section{Introduction}

This paper examines relationships between research strategies and performance in small Dedicated Biotech Firms, using Danish and Swedish biotechnology as a case. Europe's DBFs are predominantly small, with only few examples of growth to the size found in many US biotech firms. The larger US biotech firms are also the most productive and profitable (Drews 2003). For Europe the key challenge is to take an increased share of DBFs into this league (Owen 2004; Fazeli 2005), and that makes the causes of differential performance amongst smaller DBFs one of its critical issues. Several factors make the identification of these causes a difficult issue to tackle.

First, research is hampered by shortage of data in systematic, relevant form. Information produced on the biotech sector covers mainly the comparatively few biotech firms that are listed on stock exchanges. Proprietary data-providers monitor the pipelines of these firms, their research collaborations and contracts, financial changes and developments etc. Europe in particular lacks similar information for smaller, non-listed firms. Second, as observed by several authors (Nilsson 2006; Murray 2002) the translation of commercially undertaken research into performance and growth of science-based start-ups is poorly theorised.

In response to the shortage of systematic data the authors have built a database combining a variety of firm-level sources, covering all biotech firms in Denmark and Sweden. The paper presents findings from this dataset and applies it in developing metrics allowing for systematic description and analysis of the research strategies of DBFs and of their effects on the financial valuation of firms ${ }^{1}$

As for theory, since DBFs are in the business of research-based discovery, they could usefully be theorised as Simonean problem-solving agents. From this point of departure a research strategy is defined by the selection, sequencing and direction of inquiries by which a complex scientific question is addressed by a problem-solving agent. In this approach problem-solving strategies are seen largely as responses to specificities of problem architectures. Taking this approach the paper follows a three-stage argument by,

1) characterising the problem architectures addressed by different types of DBFs,

2) testing and confirming that DBFs form requisite research strategies, by which we refer to problem solving approaches developed as congruent responses to problem architectures,

3) testing and confirming that financial performance of firms is driven by achievements conforming to requisite research strategies for their particular type of problem architecture.

The paper begins by positioning in the next section its approach among different views on research as an object of strategizing, and by presenting its theoretical foundations in the resource-based view and in theories on problem solving. Section 3 develops hypotheses while the data developed to test them are presented in Section 4. Hypotheses are tested and results are interpreted in Section 5. A final discussion of results and their implications is offered in Section 6.

\footnotetext{
${ }^{1}$ DBF in this study refers to a research firm focused on drug discovery, including not only firms involved biopharmaceuticals (i.e. large molecule drugs), but also firms active in discovery of small molecule drugs, based on the use of biotechnological tools, methods, and theories.
} 


\section{Theory}

\subsection{Research strategizing as implicit dimension}

Much of the conventional wisdom on DBFs attributes their successes or failures to factors squaring uneasily with notions of research strategizing. Instead decisive factors are seen to be the quality e.g. of their science (in the academic research from which the firm typically is founded or on which it relies during its formative stages), or of their board and management. Also the pure uncertainty of research as the core activity of DBFs invites the perception that outcomes may be considered as options rather than objects for strategizing. Without insisting that the truth in this respect is either black or white, this paper pursues the opposite notion that DBFs may be analyzed as research strategizers and the extent, and the consistency with which they behave as such significantly affect their overall performance. We see strategizing, in other words, as an attribute more or less present behind the actual running of research in DBFs.

More than 20 years ago Schoonhoven took issue with popular beliefs that for high-tech firms the inherent turbulence of their markets and technologies renders strategy meaningless, arguing instead that these are precisely the conditions "Where Strategy Really Pays Off” (Schoonhoven 1984). Essentially we pursue the same argument, only now extending it further back to cover firms operating at the very well-springs of knowledge where scientific discovery and technological inventions constantly interact, as is the case in biotech discovery firms. Our argument is directed not at their style of management, not at their alliances and external network, not at their choice of business models, but at the core of their activities, which for these firms means their research. Arguing that research strategizing pays off in their performance does not diminish the importance of factors conventionally considered in this context. On the contrary, boards and managers matter precisely by the roles they play in formulating and maintaining strategic overall directions for research, an important part of which addresses the stepwise reduction of uncertainty over a sequence of partitioned research issues.

Research in large pharmaceutical firms has been the object of multiple studies to identify how it operates as a source of advantage and as an object for strategizing (Cockburn et al 2001; Dimasi et al 1995; Nightingale 2000; Chandler 2005). However, the strong emphasis in this literature on scale and scope advantages renders it less informative about issues of research strategizing in small biotech start-ups. Thse issues have been shown to differ markedly from those of large firms (Chataway and Tait 1993), confirming the more general notion in the literature that science based start-ups have a set of sui generic issues (Schoonhoven et al 1990; Nilsson 2006). Whereas research strategizing in DBF has attracted much less attention, the literature indirectly offers ample indication that DBFs indeed strategize in this part of their activity. To give just a few examples:

A sizeable literature has demonstrated not only that DBFs rely on research networks for access to opportunities and new skills, but also that learning and managerial adjustments are required from DBFs to translate this access into performance (Liebeskind et al 1996; Powell et al 1996; Gilsing and Nooteboom 2006). What exactly is involved in this firm-internal learning and adjustment is less clearly specified in the literature. The large number of collaborations documented in these studies indicate that in their selection of external projects, and extraction of direct and indirect results, firms rely on internal criteria for relevance and importance (Zucker et al 2002; Nilsson 2005). These criteria, we submit, come from a more or less explicit overall strategy for their research, defining objectives of single projects and the coherence at the portfolio level, indicating that research strategizing is one of the important skills firms must learn in order to thrive on extensive external collaboration.

Similar indications of DBFs as research strategizers grow out of the literature on their IPR, particularly in the findings that value of single patents strongly depends on achieving sufficient scope in 
their protection (Lerner 1994), and that further value comes from building portfolios in the right sequence and with the right complementarities (Lynskey 2006). Sufficient patent scope and portfolio complementarities, in other words, share the characteristic of being effects of research guided by strategic criteria at the level of single projects and spanning several subprojects within each DBF.

Along the same lines research strategizing in DBFs appears as an unarticulated dimension behind other observations on their key attributes: Systematic relationships have been demonstrated between the types of products pursued by biotech firms and their connectivity to the scientific community (Casper et al 2002); between tight agency control on part of share holders and successful commercialization of drug candidates in DBF pipelines ( Guedj and Scharfstein 2004), and between the ability to establish correspondence between research and business models as they evolve over the life cycle of single DBFs (Rothman and Kraft 2006). All these relationships would not emerge without strategic attention to direction and coherence across multiple discrete research issues addressed by DBFs, providing sufficient justification for the effort in this paper to further unpack their research strategizing.

\subsection{Building knowledge assets for problem solving - a resource based view}

Before we turn to our main argument on relationships between problem architectures and research strategies, it is useful to note that an important part of research strategizing in DBFs is concerned not with directly attacking the research object per se. Rather it is concerned with the more indirect route of building a diverse set of research tools offering indispensable effectiveness to the more direct problem solving in drug discovery (Drews 2000; Jorgensen 2004). These tools constitute knowledge assets, in the sense of representing investments for further repeated use beyond solution of a single problem.

These assets affect the overall performance of DBFs in accordance with arguments of the Resource Based View (RBV) (Wernerfelt 1984; Barney 1986; Dierickx and Cool 1989). The general claim of $\mathrm{RBV}$ is that competitive advantage may be achieved by developing and exploiting heterogeneous resources and by combining them into higher order competencies that are both the key sources of value creation and of appropriability based on non-imitability (Peteraf 1993). The concept of dynamic capability has been advanced to identify the ability to renew competencies so as to achieve congruence with changing opportunities. This capacity emerges as an effect of strategizing aimed at adapting, configuring and integrating resources and competencies (Teece and Pisano 1994).

Focusing briefly on the two key terms in the RBV argument, knowledge assets of DBFs affect their value creation not only by contributing to the quality of their science (exhaustiveness, precision etc.) but also by allowing problems to be processed at the pace required for the first mover positions without which value often evaporates in the competitive environment of DBFs. Knowledge assets, we submit, may be grouped into three categories: 1) Knowledge on therapeutic principles, i.e. proprietary or internal experiential insights on ways of accessing and controlling disease targets, 2) methods for discovering and validating drug candidates (e.g. specialised screening techniques) 3) bodies of enriched information, (e.g. proprietary libraries of small molecules or DNA sequences). Rather than providing complete predictions in the drug discovery process these knowledge assets, often referred to as a DBF's research platform, enable more effective search and interpretation of experimental procedures. For that reason they can be seen both as assets representing cumulated insights of previous findings and development of techniques, and they also can be viewed as the core of the dynamic capabilities by which these assets are further improved.

As for appropriability, these knowledge assets are crucial for building the complementarity and combinatorial uniqueness by which non-imitability is obtained. It could be argued that the focus of RBV on non-imitability has little relevance in the appropriability regime of drug discovery with its intensive patent protection against imitation. However, the findings on Danish and Swedish DBF 
start-ups presented below indicate that patents are merely one among several factors explaining financial performance, arguably because it takes time before a portfolio is formed offering the complementarities which are particularly important for its business strength (Shapiro 2001; Re-Jin Guo et al 2005). Rather than patenting finalised products, early patents often obtain a more delicate protection of territories of search and procedures from which drug candidates may evolve. The exact relationships between patents and other approaches to appropriability in early stages of the discovery cycle of DBFs is an issue in need of more research, but early patents often are best understood as allowing firms to be in the game at all, since they are a prerequisite for attracting venture capital (Lynskey 2006). However the ability to transform that capital into performance and growth to a large extent depends on those attributes of the firm, which are highlighted in RBV and in the arguments associated with dynamic capabilities.

Whereas the combinatorial possibilities of biochemistry, molecular biology and bioinformatics theoretically define a search space for drug discovery research of astronomical proportions, the avenues of discovery actually pursued by DBFs and pharmaceutical firms are much smaller in number. In fact on the most popular avenues the traffic is quite intense, i.e. several companies tend to do research that is similar in terms of targets, pathways or leads, thus forming a "strategic group”(Porter 1980; Schmid and Smith 2004). Metaphorically speaking, these firms collectively put together a jig-saw puzzle in which each player with a certain time-lag gets to see the pieces put down by the other players. The firm bringing the final pieces into place achieves a number of first mover advantages that tends to be only moderately tempered by the IPR claimed by other players in early stages of the game. For these reasons, the RBV arguments about the significance of nonimitability and fast problem solving become all the more important.

By implication research strategies of DBFs refer not only to the direct exploration of research objects, but also to the investment in knowledge assets in the form of research tools offering enhanced effectiveness in subsequent exploration. Since these two objectives in a small DBF start-up compete for the same limited resources, the issue of striking the proper balance between the two may itself safely be assumed to be a core concern for firm's research strategy.

\subsection{A cognitive contingency view on research strategies}

Turning next to the relationship between research strategies and problem architectures, let us start out by noting that a complex problem almost inherently invites strategizing as an aspect of problem solving behavior by requiring its partitioning into sub-issues. Such partitioning, in turn, is contingent on the architecture of the problem, which may be defined on several dimensions, such as the prevalence of interdependencies between its various parts, by the extent to which parts are hierarchically ordered, or by their homology(Simon 1969). Of equal importance are the cognitive resources initially available to the problem solving agent, such as her prior knowledge or her repertoire for trial-and-error procedures (Klahr 2000). These cognitive factors decide important aspects of problem solving behaviour, e.g. which part of the problem is selected as the "entry point", the sequence in which sub-issues are addressed, the extent to which sub-issues may be addressed independently of each other, whether results or successful procedures are transferable from one issues to the next etc. (Langlois 1999).

This contingency view on complex problem solving finds a useful point of departure in Simon's distinction (Simon 1969) between the two aspects of complexity in problem solving, one being an attribute of the knowledge with which problems are solved (by Simon referred to as "cognitive structures and processes"), while the other refers to the (perceived) attributes of the problem object (by Simon also referred to as the problem environment). This distinction clarifies why uncomplicated knowledge may be useful also for complex environments, provided the latter may be decomposed into sufficiently homogenous elements each of which may be addressed with the same simple repertoire of solutions. Increasing dissimilarity and interdependencies across the problem environment, 
on the other hand, calls for requisite development of complex knowledge. In such cases, which part of the problem should be selected as "entry point"? Should they be selected so as to minimise access costs, or so as to maximise reuse of initial solutions in tackling remaining parts of the environment? Some problem environments have attributes making that initial selection self-evident, while selection in other cases may be both extremely difficult and consequential for subsequent problem-solving. Drug discovery falls in this latter category, because its problem environment - the human system - from a therapeutic perspective defines a set of contingencies with fundamental implications for development of the knowledge with which the system may be accessed and controlled. The following attributes of biological systems perceived as a problem environment are particularly important:

i) Sequential causalities: Rather than being directly accessible for intervention, disease targets instead must be addressed chemically or biologically through cascades of causeeffect relationships.

ii) Multi-causal effects: Each effect in these cascades often is produced by a configuration of causal factors.

iii) Multi-effect causes: Each causal factor may have different effects depending on its configuration with other components.

iv) Selective accessibility: Only a few components offer themselves as points of access to the system, which basically is "designed" for maximum protection from external inteference. When subjected to chemical or biological manipulation, these points of access differ in the scope and depth of the causal linkages they trigger.

These four attributes turn biological systems into problem environments of exceedingly high complexity. With the advent of modern biotechnology drug discovery bifurcated into two main approaches for navigating into and through this maze of causalities, a biopharmaceutical and a small molecule approach (see Box 1 below). To a considerable extent the two approaches, in their current versions, draw on the same toolbox, which has grown out of the scientific revolutions in molecular biology and genetics ${ }^{2}$. But they differ fundamentally in their approach to the way knowledge initially is built about the system, and in turn that drives further differences in the way knowledge subsequently is reused and extended.

Inventions in biopharmaceuticals typically build on an initial highly imperfect understanding of the effects of a lead protein on a therapeutic sequence of effects. The discovery process consists in building further insights on both engineering of the protein and on the cascade it affects, to the point where controlled therapeutic results are achieved. The results achieved on this basis refer to a complex interaction, which is also exceedingly specific for both the protein and the target subset of the human system. Biopharmaceutical discovery success for the same reason represents a major challenge in reusing the complex knowledge on this interaction in the discovery of treatments for additional targets. In pursuit of such reuse other parts of the system are analysed for sub-sets with components and interdependencies that are sufficiently similar to allow significant reuse of prior problem-solving. Therefore the major challenge in research strategizing for biopharmaceutical start-ups is to capitalise on its highly complex knowledge by overcoming its extreme specificity, allowing at least portions of that knowledge to become effective also for additional therapeutic targets.

\footnotetext{
${ }^{2}$ That similarity in research tools and in a shared theoretical foundation is the reason why we group them together under the heading of "biotech firms", although some would reserve that term for biopharmaceutical firms only.
} 
Discovery in small molecule drugs, by contrast, works by exposing the problem environment to a large variety of trial and error tests of low-complexity solutions (small molecule compounds). In principle this may be done based on little prior understanding of their effects on the interdependencies by which desirable end states for the entire system come about. Instead, investment in complex knowledge creation is reserved for the tasks of a) identifying components that are particularly accessible as entry points and which also are well connected to other parts of the problem-environment, in this sense constituting the "soft spots" through which broader segments of the problem environment may be reached, and b) understanding what goes on when a specific trial solution turns out to have desirable effects, which invariably are also imperfect. Once such desirable effects are identified problem-solving focuses on understanding the cascade connecting the trial solution to these effects. The research strategy of small molecule discovery therefore typically takes it point of departure in a body of understanding of an entry mechanism giving access to multiple subsystems. That opens a considerable scope of potential disease targets, the entry points to which also frequently are claimed in patents by newly established firms. Drug discovery in this case advances by choosing one (or a few) of these potentials to build the knowledge required for effective control of its further therapeutic sequence.

\section{Hypotheses}

The main implication of this stylised presentation of the two approaches to drug discovery is that they respond to the contingencies of the problem environment of the human system with fundamentally different research strategies. Successful performance, by implication, requires firms to excel within one of two different sets of strategic requirements. The three hypotheses that structure the analysis of this paper are designed to substantiate this contingency view on strategy and performance. The two first hypotheses establish whether research in the two types of biotech firms in fact pursue different strategies. The third hypothesis tests if the firms that most effectively pursue their respective strategies also achieve superior performance.

To specify these hypotheses we translate the concept of research strategies into five constituent dimensions referring to,

\section{Knowledge complexity}

2. Solution specificity

4. Directions of problem solving

3. Search advantages

\section{Box 1: Different approaches to discov- ery in biopharmaceuticals and in small molecules}

Biotech discovery turns on matching leads to therapeutic targets through pathways that are adequately understood and controlled. But biotech firms take quite different approaches to this challenge, variations being particularly clear between biopharmaceuticals (large molecules) vs. small molecules as distinct Discovery Forms.

Biopharmaceuticals in most cases mean proteins operating as drugs, obtained by inserting humanderived gene constructs into a suitable host organism capable of producing the therapeutic protein in required quantities. A key advantage of therapeutic proteins is that if recognised as intended by the human body they may initiate natural corrective mechanisms. Such mechanisms are found e.g. in the immune system, and often consist of effective therapeutic cascades that has a complexity that is very difficult to access and control through simpler chemical drugs.

The enormous molecular complexity of proteins is the major challenge in achieving and controlling this process. Core knowledge specialisation and complementarities for biopharmaceutical firms therefore coalesce around their understanding of a highly complex lead molecule and the cascades through which its therapeutic effects are achieved. Successful effects of a large molecule in one disease area invite the firm to search for further exploitations in related therapeutic cascades.

Small molecule discovery focuses on the connection of chemical leads (of much lower complexity) to binding sites, typically found in receptors. Some receptor families appear on the membranes of many different cell-types in the human body. Correctly understood and approached these receptors may open up to pathways relevant for multiple diseases, which may be tested with a large, systematic variation of compounds. 


\section{1) Knowledge complexity and solution specificity}

In biopharmaceutical discovery key knowledge refers to two main problem areas. The first is about controlling the expression of a lead therapeutic protein, including its intricate structure and interdependencies. The second area of knowledge is about controlling its effects on a disease target via an equally intricate cascade. The combination of these two sets of properties in lead and target requires extremely complex knowledge. At the same time that knowledge produces highly specific solutions, which cannot be reused in related problem solving without further complex search and modification.

In small molecule drugs, on the other hand, knowledge in most cases centres on discovery of an effective chemical access to a specific binding site, which opens up to multiple effects in the system. The obvious attractiveness of this scope is counterbalanced by limited understanding available on each entry point regarding its pathway towards therapeutic effects.

Hypothesis 1 tests for these differences in knowledge architectures by comparing the two discovery approaches with regard to the balance between the two following attributes;

- The specificity of the access to the system is reflected in the number of different disease areas actually targeted by the DBF in its research, referred to as its therapeutic scope (TS)

- The complexity of the knowledge providing access to and control of the system is reflected in its heterogeneity, i.e. the number of different knowledge domains, tools, and techniques that are required for or produced by this knowledge, referred to as its knowledge heterogeneity $(\mathrm{KH})^{3}$

The ratio of $\mathrm{KH}$ over TS therefore is expected to have higher average value in biopharmaceutical as compared to small molecule research:

\begin{tabular}{|l|l|}
\hline Issue & $\begin{array}{l}\text { Different relationships between knowledge complexity and solution } \\
\text { specificity }\end{array}$ \\
\hline Hypothesis 1 & $\begin{array}{l}\text { Knowledge heterogeneity per disease area is higher in biopharmaceutical DBFs } \\
\text { than in small molecule DBFs. }\end{array}$ \\
\hline
\end{tabular}

\section{2) Search advantages and directions in problem solving}

For biopharmaceuticals the key advantage for further problem solving is that the complex knowledge on proteins and their effects on cascades may be partially reused to access additional therapeutic targets, provided they are regulated through cascades sufficiently overlapping with or resembling their first achievement. Further search and discovery therefore is driven by pursuit of re-use of knowledge for new targets, i.e. directing problem solving to expand therapeutic scope per unit of knowledge heterogeneity, hence decreasing the KH/TS ratio.

Small molecules have the very different advantages of easier trial-and-error search for potential therapeutic effects, allowing more effective prioritisation of pathways selected for deeper and focused research. Once this selection has been made, further inventiveness must focus on building knowledge and control beyond the binding site. This direction requires further problem solving to

\footnotetext{
${ }^{3}$ The dimensions of KH and TS are conceptually independent of its other. That is, different spans of therapeutic scope may be offered by the same level of knowledge heterogeneity, depending entirely on the intricacy of the lead and of the pathways addressed in the therapeutic approach.
} 
be directed at expansion of knowledge heterogeneity per unit of therapeutic scope, hence increasing the $\mathrm{KH} / \mathrm{TS}$ ratio.

\begin{tabular}{|l|l|}
\hline Issue & Directions of problem solving \\
\hline Hypothesis 2 & $\begin{array}{l}\text { Increasing inventiveness produces decreasing KH/TS ratios in biopharmaceutical } \\
\text { DBFs and increasing KH/TS rations in small-molecule DBFs. }\end{array}$ \\
\hline
\end{tabular}

\section{3) Direction of achievements affecting firm valuation}

In biopharmaceutical discovery the main barrier for extending knowledge from previous problem solving comes from the high specificity of the therapeutic cascades. This specificity means that opportunities for re-use of knowledge are both difficult to identify, and once they are found will require substantial complementary discoveries to make them effective as drug targets. Overcoming this barrier critically affect the value of the problem solving capability of the firm. I.e. for these firms increasing valuation is a function of decreasing KH/TS value over time.

Small molecule firms must overcome the different barrier of building an understanding of a complex pathway, without the benefit available to biopharmaceutical discovery of re-using complex patterns. For them valuable problem solving centres on progress in validating and substantiating their understanding for any single therapeutic target. I.e. their valuation increases as a function of increasing $\mathrm{KH} / \mathrm{TS}$ values.

\begin{tabular}{|l|l|}
\hline Issue & Effects on the valuation of DBFs \\
\hline Hypothesis 3 & $\begin{array}{l}\text { Valuation of DBFs increases with falling levels of KH/TS ratio in biopharmaceu- } \\
\text { tical firms and with rising levels of the ratio in small molecule DBFs. }\end{array}$ \\
\hline
\end{tabular}

Suitable data to test these three hypotheses would come from a population of young, small biotech firms active in biopharmaceutical or in small molecule drug discovery research, with a minimum of overlap between the two approaches within one and the same. The two next sections demonstrate that these requirements are largely met by DBFs in Denmark and Sweden, and the methodology is presented with which data on these firms has been collected and transformed into relevant metrics.

\section{Data and methodology}

Data for this paper has been extracted from the SCANdinavian BIoTech database (SCANBIT), developed by the authors to cover Scandinavian biotech firms. Taking the firms as its key unit, SCANBIT brings together data extracted from multiple sources, including financial accounts, bibliographic sources, and information provided by firms primarily via Internet sites and other public documents. All patents of each firm are recorded with their IPC codes, application date, date granted, assignees, and description of the patented technology. Bibliographic sources comprises scientific and press articles. Data sources are regularly scanned and examined to continuously update SCANBIT.

\subsection{Firms}

The issues examined in this paper are concerned with problem-solving in DBFs specialised in drug discovery, and only firms from that category are included in the analysis below. Data were extracted on Swedish and Danish firms, which cover most of Scandinavian firms in this category (only 12 quite small drug discovery DBFs operate in Norway). A total of 43 Swedish and the 49 Danish discovery DBFs have emerged since 1990 evenly divided in specialisations in biopharmaceutical and in small molecule discovery, but with some differences between the two countries. The 
presentation of firms by year of entry in Fig. 1 shows that after 2001 small molecule firms outnumber biopharmaceutical firms in Denmark. In Sweden, on the other hand, bio-pharmaceutical DBFs drive the increase of firms since 1997. Fig. 1 also brings out that it is a young population of firms, which largely emerged in the mid-1990s and one half of which was less than 5 years old in 2003, the latest year for which we bring data. Of the total of 92 firms 11 have closed down, ceased activity, or integrated with other firms, leaving 81 active firms by 2003, the latest year for which data are used for the present analysis.

Fig. 1: Number of firm establishments by year, nationality and discovery approach

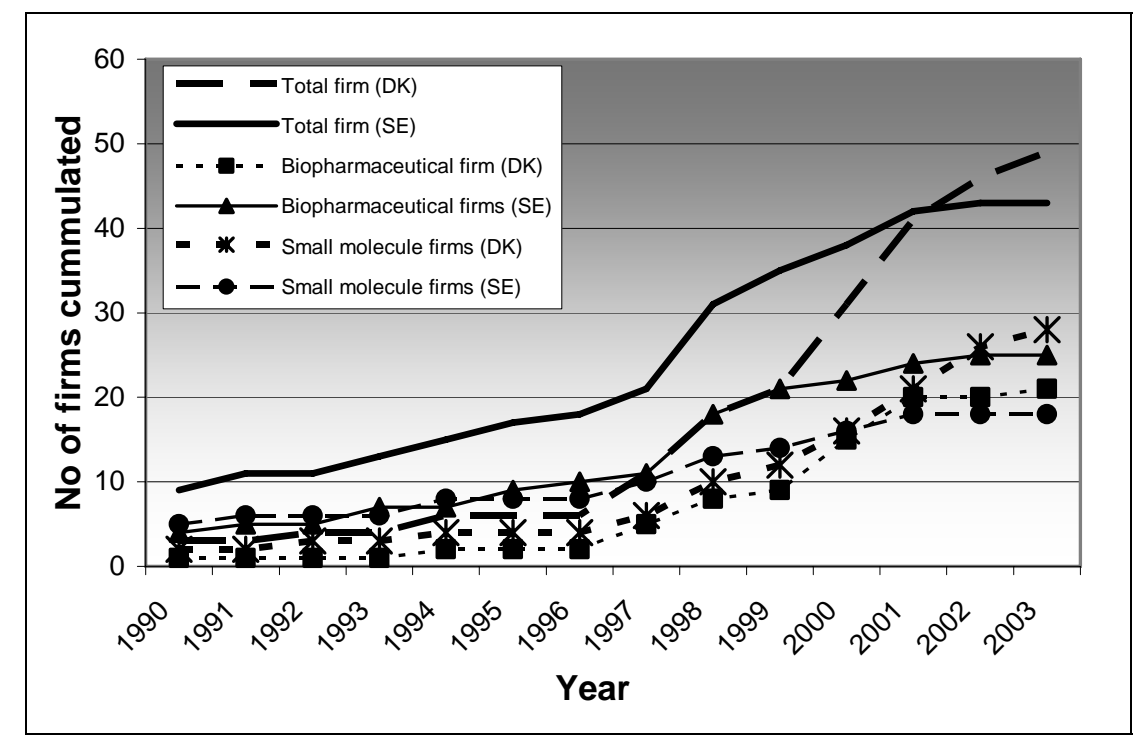

\subsection{Variables}

\subsubsection{Valuations}

The DBFs in pharma discovery examined in this paper are financed primarily by venture capital and in most cases are not yet profitable. Conventional financial metrics, consequently, do not adequately reflect their performance, and stock rates are available as metrics only for the 9 discovery DBFs listed on the Swedish and Danish exchanges. As an alternative we calculate an Adjusted Index of Share Value.

AISV measures the rates with which shares are acquired, normalised to an identical nominal share value, thus reflecting not the value of the firm as an effect of its size, but instead expected returns per equally sized units of investments. For unlisted firms these rates vary from one investment round to the next and this valuation of firms per round of investment is our basic unit of analysis. Data for this calculation have been extracted from the record for all new equity which firms are mandated to file with Danish and Swedish Commerce and Companies Agencies.

Information on investment rounds or share values is available only for 70 firms. Nine firms are listed on the Danish or Swedish stock exchange. Performance measures thus have to be determined from two approaches depending on whether the firm, at the time of valuation, is listed or not. The number of investment rounds per firm is presented in Fig. 2 
Fig. 2: Number of capital rounds pr firm

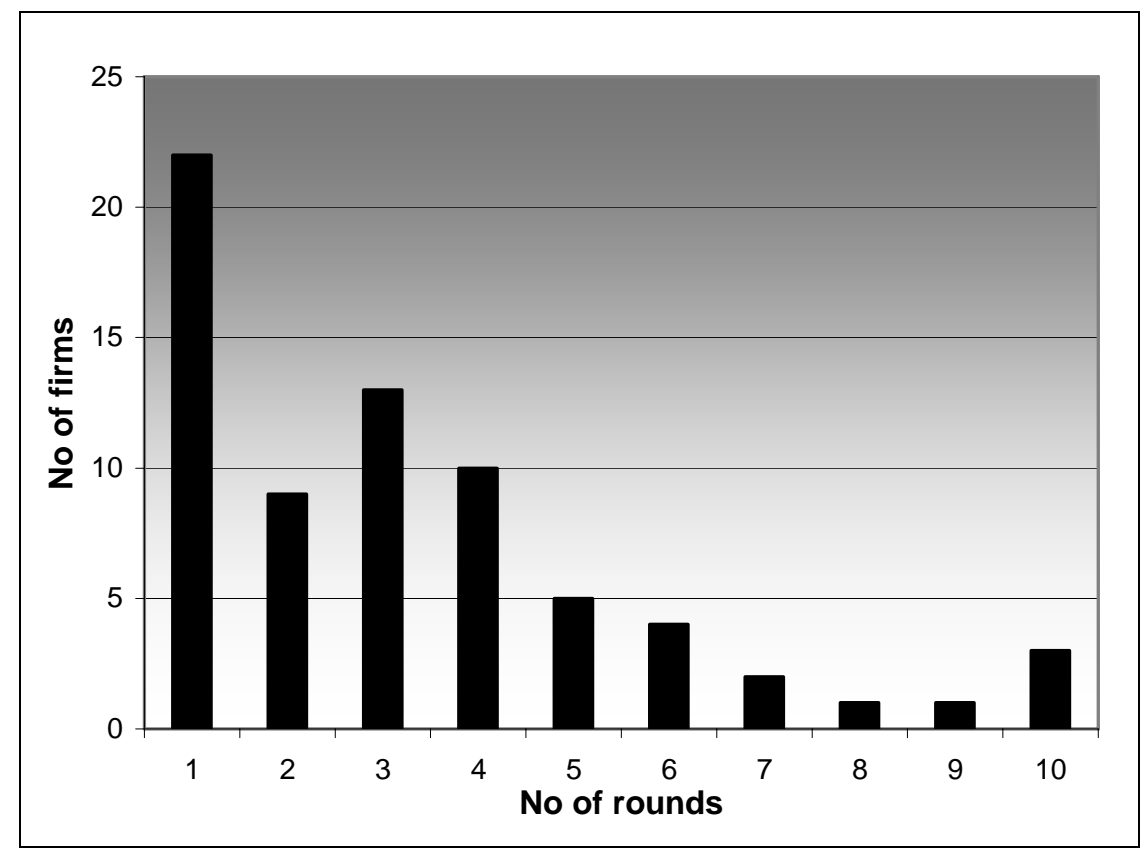

AISV is calculated for each firm and each year by means of the following intermediate metrics:

1) Share value: For firms listed on the stock exchange, the value per share is available on a daily basis. The share value for a given year is calculated as the average daily closing price per share for each firm, which reduces fluctuations during the year in the market assessment of firm values. For non-listed firms share values are based on the total amount invested in each round divided by the number of new shares committed. An Index of share value is calculated as the share value divided by the nominal share value, normalising shares to identical units of nominal value. Only rounds involving new issued shares and capital increases with share premium are taken into account, to reduce the risk of biased and internal determination of share prices, resulting from converting debts or warrants exercised into share capital. New investments are assumed to better mirror a market assessment of the firm.

2) Postmoney value refers to the total value of a firm. It is calculated as the share value multiplied by the total number of shares committed. For listed firms, postmoney value is the market capitalization value, calculated as the average daily closing price in each year for a given firm multiplied with the number of stocks committed. Postmoney value for non-listed firms is calculated as share value multiplied by the total number of shares committed as per each round of capital inflow. This value corresponds to the amount an investor has to invest to acquire the whole firm if buying at the price resulting from the latest round. 13 firm valuations for years falling between capital rounds are linear interpolations. Of all the 229 valuations, 167 relate to rounds in non-listed firms, and 62 to firms listed on the stock exchange (Table 1). 
Table 1: Distribution of firms and rounds by discovery approaches

\begin{tabular}{|c|c|c|c|c|c|c|}
\hline \multicolumn{2}{|r|}{ Discovery Field } & Firms & $\begin{array}{l}\text { Observed invest- } \\
\text { ment rounds }\end{array}$ & Interpolations & $\begin{array}{l}\text { Stock } \\
\text { rates }\end{array}$ & $\begin{array}{l}\text { Total no of index } \\
\text { values on AISV }\end{array}$ \\
\hline \multirow{3}{*}{$S E$} & Biopharmaceutical & 19 & 51 & 0 & 16 & 67 \\
\hline & Small molecule & 13 & 40 & 0 & 20 & 60 \\
\hline & Total & 32 & 91 & 0 & 36 & 127 \\
\hline \multirow{3}{*}{$D K$} & Biopharmaceutical & 17 & 33 & 6 & 17 & 56 \\
\hline & Small molecule & 21 & 30 & 7 & 9 & 46 \\
\hline & Total & 38 & 43 & 13 & 26 & 102 \\
\hline \multicolumn{2}{|c|}{ Grand total } & 70 & 154 & 13 & 62 & 229 \\
\hline
\end{tabular}

3) Adjustment ratio. The Index of Share Value does not take into account systemic differences in share value assessments between listed and non-listed firms, the latter category of firms persistently having a higher scoring on the Index of Share Value. Since we are interested in comparing the total population of DBFs over time, including both listed and non-listed firms, we correct for this difference by calculating an Adjustment ratio for differences between listed and non-listed firms for each year. For each of the two groups total postmoney value is divided by total nominal value. The rate by which results for non-listed forms exceeds that of listed firms forms the Adjustment ratio, presented in Fig. 3.

Fig. 3: Factor adjusting Index of Share Value

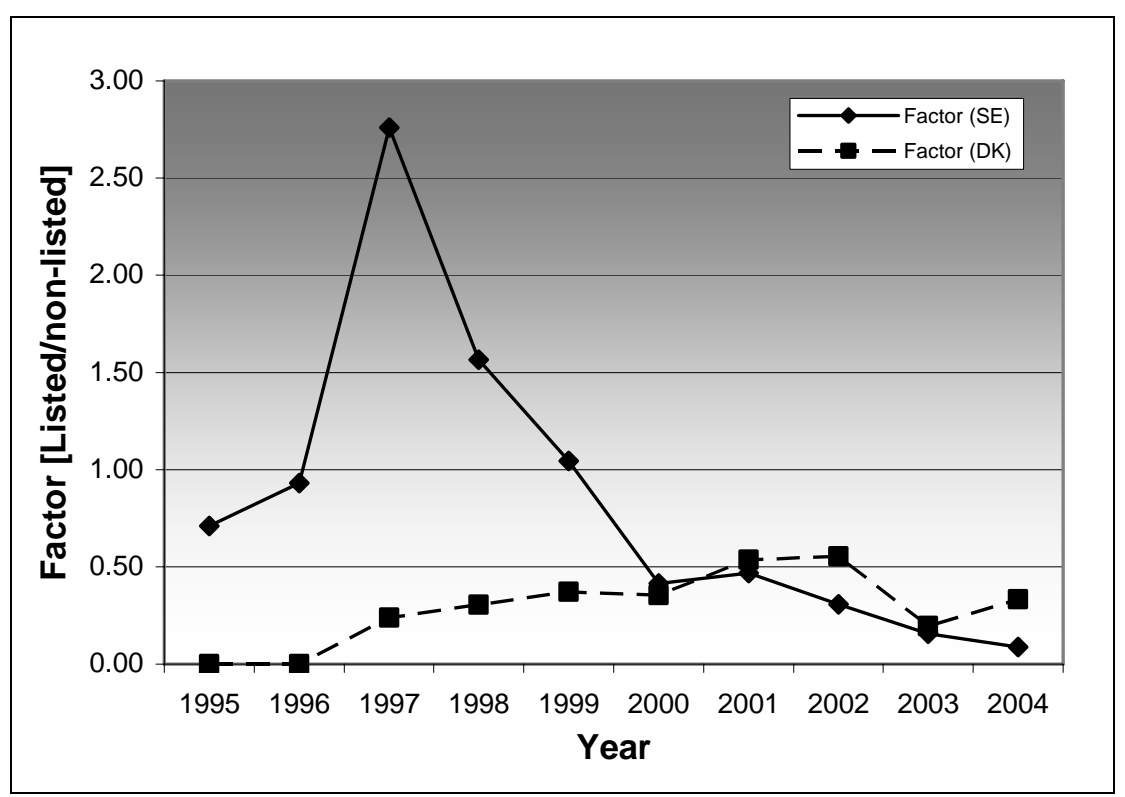

4) Adjusted index of share value for listed forms is identical with Index of Share Value, while for non-listed firm the index is deflated by the Adjustment ratio. The Adjusted Index AISV measures financial performance corrected for effects of firm size and for systematic inflation of valuation rates for non-listed firms. AISV will be the key metric for the valuation of firms in the analysis below.

\subsubsection{Knowledge heterogeneity $(\mathrm{KH})$}

Indicators to represent the heterogeneity of knowledge assets play an important part in the analysis presented below. "Knowledge-relatedness" or "technological proximity", as a measure of techno- 
logical heterogeneity between firms, has been applied in a number of previous contributions. These methods include various techniques ranging from measuring $R \& D$ expenditures and the distribution of outputs between different industries (Scherer 1982), the distribution of patents over technology fields (Jaffe 1986; Jaffe 1989; van Raan and Engelsman 1993), and the combination of classification codes in individual patents (Verspagen 1997; Breschi et al 2003). In this paper we apply an original bibliometric method of measuring the level of heterogeneity within firms, referred to as the H-index. This index is based on the main IPC code of each patent. IPC codes are translated into a three level categorisation, referred to as H-codes, in which level 1 indicates the highest aggregation of technological fields, while level 3 gives the most detailed specification of technological fields ${ }^{4}$. The level of heterogeneity within each firm is measured by the number of relationships between dissimilar H-codes for all the firm's patents $(\mathrm{N})$, normalised by the total number of relationships between patents [N(N-1)/2]. All relationships between identical H-codes are given a score of 0 . Relationships between dissimilar $\mathrm{H}$-codes at level 1 are given the value 1 . Dissimilarities at level 2 take the value of 0,5 , while differences on level 3 score 0,25 .

An $\mathrm{H}$-index value of 1 indicates a firm with all patents falling into different technological fields at level 1 , while an index value of 0 corresponds to a firm with all its patents falling within a single $\mathrm{H}$ code. Firms with less than 2 patents are omitted and therefore not assigned any value, so that $\mathrm{H}$ index observation are available for a total 62 firms. A more detailed presentation of the H-index is available in (Dahlgren, Jensen, and Valentin 2004).

Roughly 2/3 of the firms for which the H-index may be calculated in 2003 had scores between 0.25 and 0.75 (Fig. 4). Tests confirm that a firm's $\mathrm{H}$-index value is unrelated to its number of patents. I.e. the index reflects not its level of inventiveness, but the heterogeneity of the knowledge on which its entire patent portfolio is based.

\footnotetext{
${ }^{4} \mathrm{H}$-codes aggregate the 5-level IPC system along two dimensions. "Vertically", IPC levels 1 and 2 are combined into H-level 1, while IPC levels 4 and 5 are combined into level 3. The IPC codes now appearing on three vertical H-levels, are aggregated further, horizontally, on each of the 3 levels. H-level 1 has 9 categories, level 2 has 19 categories, and level 3 has 17. To exemplify, the five IPC levels of IPC “C12Q-001/18” signify the following:

IPC-Level 1: $\quad \mathrm{C}$ : Chemistry and metallurgy

IPC-Level 2: $\quad$ C12: Biochemistry; beer, spirits, wine or vinegar; microbiology or enzymology, mutation or genetic engineering.

IPC-Level 3: $\quad$ C12Q: Measuring or testing processes involving enzymes or micro-organisms, compositions or test papers therefore, processes of preparing such compositions, condition-responsive control in microbiological or enzymological processes,

IPC-Level 4: $\quad$ C12Q-001: Measuring or testing processes involving enzymes or micro-organisms and compositions therefore and/or processes of preparing such compositions.

IPC-Level 5: $\quad$ C12Q-001/18: Measuring or testing processes involving viable micro-organisms testing for antimicrobial activity of a material.

This IPC code is translated into the H-code “7.2.0” in the following way: Category 7 on H-level 1 corresponds to C12 in the IPC system. Category 2 on H-level 2 corresponds to Q on IPC level 3. Category 0 on H-level 3 corresponds to 001 on IPC levels 4 and 5.
} 
Fig. 4: Firms by level of knowledge heterogeneity

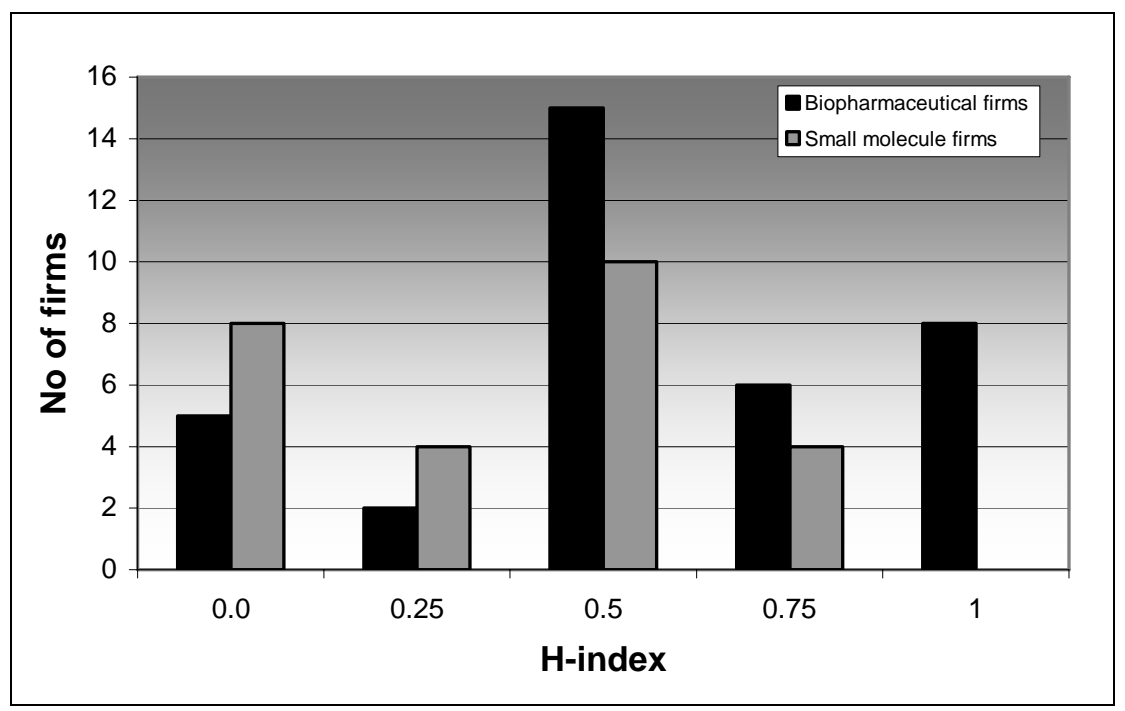

\subsubsection{Therapeutic scope (TS)}

Values for therapeutic scope of the company per each year take their point of departure in the number of disease groups in which the company reports activity in 2003. A total of 85 firms provide date on disease groups. We use a highly aggregated classification into 12 disease groups, so that activity across several groups for a small DBF signals considerable diversity. Observations are available for 85 firms. Fig 5 present the percentage shares of firms for specific numbers of disease groups, separately for the two discovery approaches.

Most firms are active in 1-2 disease groups only, and very few firms operate in four groups or more. There is a slight tendency for more disease groups per firm in small molecule discovery.

Fig. 5: Firms by number of disease groups targeted by their research.

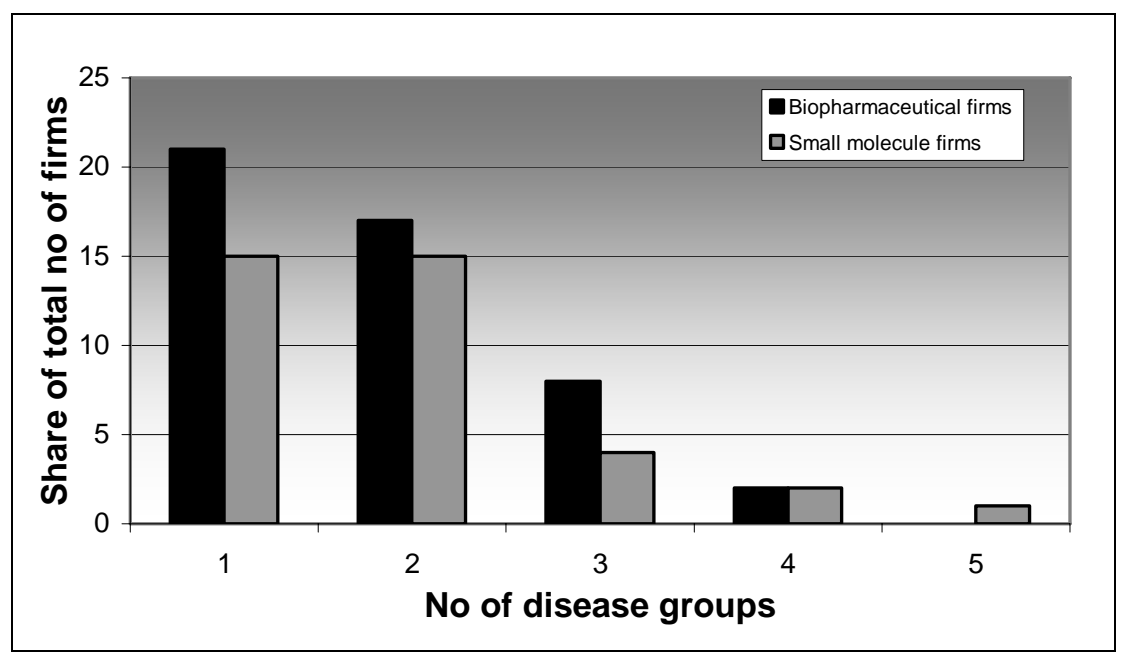

A regression shows the number of disease groups addressed by firms in 2003 to be a function of firm age ( $p<0,0001)$ with yearly increments of 0.05715 . This coefficient is applied in backward adjustments of values for Therapeutic Scope until the level of 1 is reached. (Firms giving no specific information on therapeutic fields are coded “missing” on this variable.) 


\subsubsection{Approaches in pharmaceutical discovery}

SCANBIT maps the discovery approach(es) of each firm into a detailed classification. Most firms pursue one approach only, but a few engage in two or even more. Based on the approach that is predominant in each case, firms have been regrouped into the following two main types of discovery fields: 1) Bio-pharmaceuticals and 2) Small molecule drugs.

\subsubsection{Inventiveness}

Inventiveness of each firm is measured by its cumulated number of patent applications by the year of the investment round for non-listed firms or the year for calculation of the average stock rates for listed firms (labeled 01BUB).The patent application date is used so as to get as close as possible to the time of invention. Fig. 6 present firms by the accumulated number of patents as per 2003 (omitting the large Danish DBF, Neurosearch A/S, with its 129 patents and 161 employees). Ten firms have no patents. One third of the firms have 3 patents or less.

Fig. 6: Firms by cumulated number of patents 2003

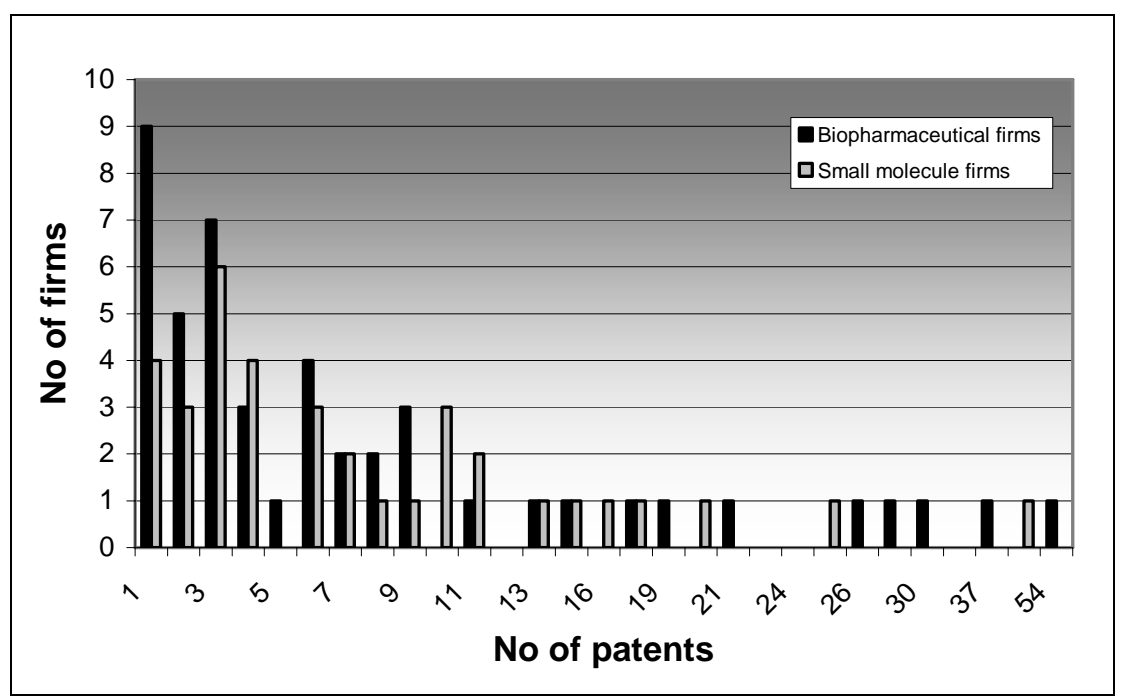

\subsubsection{Bubble effect on firm valuations}

The bursting high-tech bubble in 2001 profoundly affected investments in the firms studies here. Fig. 7 shows the steep increase in investment (in Danish crowns) up until early 2001, followed by a steep decline. In the analysis below we control for this effect by introducing a dummy with years after 2001 given the value of 1 . 
Fig.7: Total amount pr year in Mkr [non-listed firms]

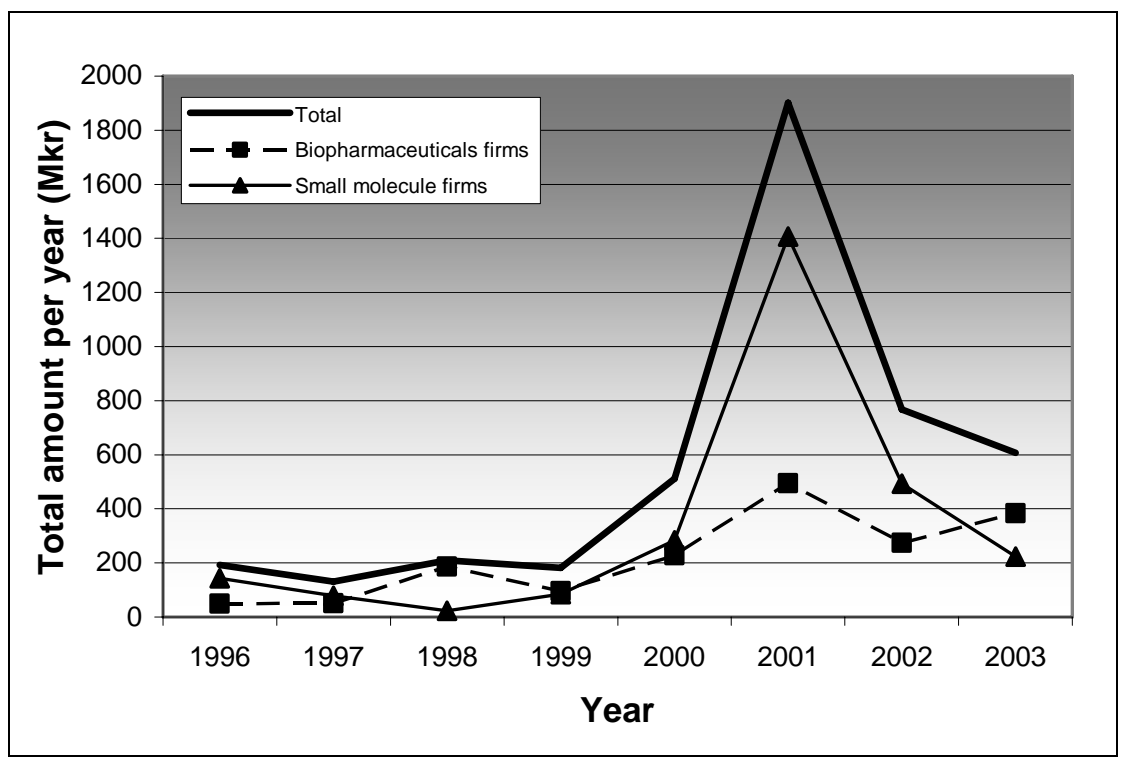

\section{Tests of hypotheses}

\subsection{HYP 1}

Table 2 presents variables applied in the tests of Hypotheses 1, 2 and 3,

Table 2: Variables used in test of Hypotheses 1, 2, 3

\begin{tabular}{|c|c|c|c|}
\hline $\begin{array}{c}\begin{array}{c}\text { Status in } \\
\text { model }\end{array} \\
\end{array}$ & Role in hypothesis & Indicator & $\begin{array}{l}\text { Variable } \\
\text { acronym }\end{array}$ \\
\hline $\begin{array}{l}\text { Dependent } \\
\text { Variable }\end{array}$ & $\begin{array}{l}\text { Rate by which the firm is valu- } \\
\text { ated in each round of investment }\end{array}$ & (log) adjusted rate index & logAISV \\
\hline \multirow{5}{*}{$\begin{array}{l}\text { Independent } \\
\text { variables }\end{array}$} & Inventiveness & $\begin{array}{l}\text { Number of patents until the year of the in- } \\
\text { vestment round }\end{array}$ & Pat \\
\hline & Knowledge heterogeneity & $\begin{array}{l}\text { Value at H-index as per each investment } \\
\text { round }\end{array}$ & $\mathrm{KH}$ \\
\hline & Therapeutic scope & $\begin{array}{l}\text { The number of therapeutic areas in which he } \\
\text { DBF's is active at each investment round }\end{array}$ & TS \\
\hline & $\begin{array}{l}\text { Ratio of Knowledge Heterogene- } \\
\text { ity per unit of therapeutic scope }\end{array}$ & $\begin{array}{l}\text { H-indix divided by number of therapeutic ar- } \\
\text { eas as per each investment round }\end{array}$ & KH/TS \\
\hline & Control variable & $\begin{array}{l}\text { Control for the effect of the IT-crash in } 2000 \\
\text { on the adjusted rate index }\end{array}$ & Inddev \\
\hline
\end{tabular}

The first hypothesis submits that Knowledge heterogeneity per disease area is higher in biopharmaceutical DBFs than in small molecule DBFs. It is tested by comparing with Anova analysis average $\mathrm{KH} / \mathrm{TS}$ ratios for the two segments of biopharmaceutical and small molecule firms, at the point in time of each capital round for each firm. Results are presented in Table 3, confirming a ratio in biopharmaceutical DBFs about 30\% higher than the ratio for small molecule firms (a difference significant at the $5 \%$ level) 
Table 3: ANOVA tests of difference between biopharmaceutical and small molecule DBFs in average scores on the $\mathrm{KH} / \mathrm{TH}$ ratio

\begin{tabular}{lccc}
\hline \multirow{2}{*}{ Strategy dimension } & \multicolumn{3}{c}{ ANOVA test of differences of average score } \\
\cline { 2 - 4 } & Biopharmaceutical & Small molecule & $\begin{array}{c}\text { Overall } \\
\text { mean }\end{array}$ \\
\hline Average KH/TS Ratio scores & $0.4078^{* *}$ & $0.3078^{* *}$ & 0.3699 \\
\hline $\mathbf{N}$ & 74 & 45 & 119 \\
\hline $\begin{array}{l}\text { Three outliers omitted, all referring to portfolios of only two patents as per the initial capital } \\
\text { round of firms } \\
\text { Levels of significance as indicated by } *=10 \% \text { level, } * *=5 \% \text { level and } * * *=1 \% \text { level. }\end{array}$
\end{tabular}

The confirmation of hypothesis 1 documents a tendency in the two DBF segments to differ in their basic knowledge architectures. Compared to small molecule DBFs, biopharmaceutical firms on average build significantly broader and more heterogeneous knowledge per disease target addressed in their inventions.

\subsection{HYP 2}

Hypotheses 2 and 3 are tested with regressions using variables which have their descriptive statistics presented in Table 4.

Table 4: Descriptive statistics for variables in regressions testing hypotheses 2 and 3

\begin{tabular}{|c|c|c|c|c|c|c|c|c|c|c|}
\hline \multirow{2}{*}{ Name of variable } & \multicolumn{5}{|c|}{ Biopharmaceutical firms } & \multicolumn{5}{|c|}{ Small molecule firms } \\
\hline & $\mathrm{N}$ & Mean & Std dev & Min & Max & $\mathrm{N}$ & Mean & Std dev & Min & Max \\
\hline $\log (A I S V)$ & 109 & 2.874 & 1.259 & -0.590 & 5.365 & 99 & 3.100 & 1.405 & -0.365 & 6.286 \\
\hline KH/TS-ratio & 68 & 0.388 & 0.294 & 0.000 & 1.000 & 44 & 0.313 & 0.201 & 0.000 & 0.754 \\
\hline $\log (K H / T S-r a t i o)$ & 59 & -0.984 & 0.622 & -3.119 & 0.000 & 38 & -1.153 & 0.596 & -2.787 & -0.282 \\
\hline$K H$ & 78 & 0.662 & 0.307 & 0.000 & 1.000 & 56 & 0.474 & 0.270 & 0.000 & 1.000 \\
\hline TS & 102 & 1.899 & 0.837 & 1.000 & 4.057 & 87 & 1.899 & 0.989 & 1.000 & 5.057 \\
\hline Pat & 115 & 8.296 & 11.202 & 0.000 & 54.000 & 104 & 14.442 & 28.389 & 0.000 & 129.000 \\
\hline $\log ($ Pat $)$ & 99 & 1.605 & 1.191 & 0.000 & 3.989 & 75 & 1.881 & 1.544 & 0.000 & 4.859 \\
\hline $01 B U B$ & \multicolumn{5}{|c|}{$71.30 \%(1)$} & \multicolumn{5}{|c|}{$59.62 \%(1)$} \\
\hline
\end{tabular}

Hypothesis 2 (Increasing inventiveness produces decreasing KH/TS ratios in biopharmaceutical DBFs and increasing KH/TS rations in small-molecule DBFs) is tested in regression analysis with $\mathrm{KH} / \mathrm{TS}$ ratios as the dependent variable (Table 5). The independent variable is the level of inventiveness of the firm, as indicated by its accumulated number of patents, and both variables are measured at the time of each capital round for each firm. Tests are made separately for the two segments of biopharmaceutical and small molecule DBFs. Log transformation is applied to both dependent and independent variable, estimates in other words indicating how the rate of increases in patenting affect the rate of changes in on the $\mathrm{KH} / \mathrm{TS}$ ratio. 
Table 5: Effects of increasing number of inventions on KH/TS ratios. Separate regression analyses for biopharmaceutical and for small molecule DBFs

\begin{tabular}{cccc}
\hline & \multicolumn{2}{c}{ Dependent variable $\mathbf{L o g}($ KH/TS Ratio) } \\
\cline { 2 - 4 } Independent variables & Model 1: & Model 2: \\
& Biopharmaceutical firms & Small molecule firms \\
& $(\mathrm{N}=115)$ & $(\mathrm{N}=104)$ \\
\hline Intercept & $-0.181(0.164)$ & $-1.836^{* * *}(0.354)$ \\
Log(Pat) & $-0.411^{* * *}(0.060)$ & $0.227^{* *}(0.099)$ \\
\hline \multirow{2}{*}{ Model } & Pr $>$ F & 0.0001 & 0.0265 \\
& Adj R-sqr & 0.3326 & 0.2145 \\
& Df & 58 & 38 \\
\hline
\end{tabular}

- $\quad$ Robust Standard errors are given in parentheses under each estimate

- $\quad$ Levels of significance as indicated by $*=10 \%$ level, $* *=5 \%$ level and $* * *=1 \%$ level.

Increasing inventiveness is found, in both discovery approaches, to significantly (at $1 \%$ and $5 \%$ levels) affect the levels of KH/TS ratio. The ratio shifts at a rate of $0.2-0.4$ of the rate of increase in patenting. Equally important, however, these shifts take the ratio in opposite directions for the two discovery approaches. Addition of further inventions to the portfolio, in other words, for biopharmaceutical DBFs has the objective of shifting the balance towards identifying additional promising disease targets, so as to capitalise further on the heterogeneous knowledge already developed by the firm. For small molecule DBF, conversely, the objective is not to add further potential disease targets to the portfolio but to build broader knowledge on whatever therapeutic pathways seems particularly promising.

\subsection{HYP 3}

Hypothesis 3 (Valuation of DBFs increases with falling levels of KH/TS ratio in biopharmaceutical firms and with rising levels of the ratio in small molecule DBFs) is tested and presented in Table 6A-B in two separate sets of OLS regression models for biopharmaceutical firms only, and for small molecule firms only ${ }^{5}$. A log transformation of the dependent variable is applied, to bring out more clearly the rate with which effects are brought about and to handle large variations appearing in a small subset of valuations.

Tables 6 A and B present findings using the same structure with 4 models, each testing one of the independent variables, all of which include Inddev and PAT as controls.

\footnotetext{
${ }^{5}$ Results from mixed models are not presented because they require observations ideally to be available for each firm in each year. The present dataset falls short of these requirements in several aspects, since i) investment rounds occur in highly irregular patterns, ii) a number of firms do not exist during the whole period of study, iii) many firms have only one investment round (compare Fig. 2). To test for effects for specific companies a mixed model nevertheless was applied and show no significant relationships for any firms.
} 
Table 6: Effect on firm valuations of scores on KH/TS ratios. Separate regression analyses for biopharmaceutical and for small molecules DBFs

\begin{tabular}{|c|c|c|c|c|}
\hline \multirow{3}{*}{ Independent Variables } & \multicolumn{4}{|c|}{ Dependent variable Log(adjrateidx) } \\
\hline & \multicolumn{4}{|c|}{ 6A: Biopharmaceutical firms $(\mathrm{N}=115)$} \\
\hline & Model 1 & Model 2 & Model 3 & Model 4 \\
\hline Intercept & $3.135 * * *(0.254)$ & $3.999 * * *(0.255)$ & $2.795 * * *(0.495)$ & $4.146 * * *(0.233)$ \\
\hline$K H$ & & $0.886 * *(0.358)$ & & \\
\hline TS & & & $0.275^{*}(0.163)$ & \\
\hline KH/TS Ratio & & & & $-0.951 * *(0.489)$ \\
\hline Inddev & $-0.388(0.268)$ & $-0.347(0.241)$ & $-0.449(0.316)$ & $-0.525 * *(0.0245)$ \\
\hline Pats & $0.001(0.009)$ & $-0.009(0.009)$ & $-0.012(0.135)$ & $-0.034 * *(0.014)$ \\
\hline Pr $>$ F & 0.3456 & 0.0054 & 0.0354 & 0.0007 \\
\hline Adj R-sqr & 0.0201 & 0.1151 & 0.0643 & 0.1548 \\
\hline$D f$ & 109 & 75 & 97 & 65 \\
\hline
\end{tabular}

\begin{tabular}{|c|c|c|c|c|}
\hline & \multicolumn{4}{|c|}{ 6B: Small molecule firms $(N=104)$} \\
\hline & Model 1 & Model 2 & Model 3 & Model 4 \\
\hline Intercept & $3.484 * * *(0.273)$ & $3.523 * * *(0.489)$ & $3.656 * * *(0.408)$ & $3.099 * * *(0.366)$ \\
\hline$K H$ & & $0.699(0.709)$ & & \\
\hline TS & & & $-0.281 *(0.141)$ & \\
\hline KH/TS Ratio & & & & $2.169 * *(0.844)$ \\
\hline Inddev & $-0.451(0.300)$ & $-0.682 *(0.358)$ & $-0.056(0.326)$ & $-0.664 * *(0.307)$ \\
\hline Pat & $-0.007 * *(0.003)$ & $-0.011^{* * *}(0.003)$ & $-0.005^{* *}(0.003)$ & $-0.011^{* * *}(0.003)$ \\
\hline $\operatorname{Pr}>\mathbf{F}$ & 0.0224 & 0.0020 & 0.0616 & 0.0035 \\
\hline Adj R-sqr & 0.0436 & 0.1478 & 0.0688 & 0.3102 \\
\hline$D f$ & 99 & 55 & 82 & 43 \\
\hline
\end{tabular}

- $\quad$ Robust Standard errors are given in parentheses under each estimate

- $\quad$ Levels of significance as indicated by $*=10 \%$ level, $* *=5 \%$ level and $* * *=1 \%$ level.

- 10 outliers omitted, all referring to portfolios of only two patents and to very small investment made in the initial round of firms

The main test is provided by model 4, which confirms HYP 3. Valuation of DBFs is clearly driven by shifts in the predicted opposite directions of the KH/TS ratio for the two discovery approaches. At the same time model 4 offers additional insights on the role of inventiveness as reflected in Pat. In both versions of model 4, Pat comes out with significant estimates close to zero. What drives valuations, in other words is the direction of inventiveness as expressed in the KH/TS ratio, which must be moved in opposite directions for firms operating in the two discovery approaches. When that direction plays out its effects on valuations, then the rate of inventiveness quite consistently is inconsequential for the valuation of firms. In that sense the premium for valuations comes not from the rate of inventiveness per se, but from strategizing consistently on the other two dimensions of research strategies.

In model 4 the negative significant slope on INDDEV indicate a robust effect of the decline in venture financing after 2001.

Significant estimates also appear in some of models for KH and TS as separate variables, however yielding consistently lower $\mathrm{R}^{2}$ compared to what is achieved with the ratio in model 4 . That is particularly the case for small molecule DBFs, the $\mathrm{R}^{2}$ of which (0.31) indicates that a considerably share of variations in valuations for this discovery approach is explained by model 4. 


\subsection{Interpretations}

According to the cognitive contingency view, presented in the theory section, problem solving is shaped by the architecture of the problem it addresses. The attribute of problem architectures playing a particularly important role in therapeutic pathways, concerns their interdependencies. Biopharmaceutical DBFs, we argue, by working through engineering of proteins and controlling their effects on complex cascades, initially address a larger set of interdependencies in the system as compared to small molecule discovery. It is this difference in problem architectures addressed by the two approaches, which requires biopharmaceuticals from the outset to tackle a broader and more heterogeneous set of problems, which, in turn, appears as an attribute of the knowledge they build during the early stages of the company. This is the conjecture about relationships between problem architectures, problem solving, and resultant knowledge, which we find confirmed is the verification of HYP 1.

To oversimplify the case, after the first round of problem solving, small molecule firms have discovered multiple potential points of access to therapeutic effects, but have fairly scant understanding of each of them. Biopharmaceuticals, on the other hand, comes out of initial problem solving with highly complex knowledge about therapeutic effects, which are extremely specific. Therefore further research for either approach must be strategized so as to capitalize on initial results, while also overcoming their barriers. For biopharmaceuticals that research strategy means extending the highly specialised knowledge already achieved to additional disease targets. Small molecule firms, conversely, must build further knowledge directed at a selected disease $a^{2}{ }^{6}$. That is the conjecture, translated into opposite directions of the $\mathrm{KH} / \mathrm{TS}$ ratio for increasing number of patents, which is confirmed by the verification of HYP 2 .

The third and last part of our argument (HYP 3) refers to research strategies as they affect the valuation of firms. To interpret the verification of HYP 3 the implication of HYP 1 should be noted, i.e. that the initial drive of the two discovery approaches, given their problem architectures, is to form high, resp. low KH/TS ratios. Those are the natural propensities of firms in the two approaches, so to speak, and they attract their initial venture capital based on the intermediate results expected from these initial ratios. Bringing the ratios to reverse their direction is much less a "natural propensity". For a biopharmaceitcal research team it is considerably more challenging to transfer their knowledge into new disease targets, than it is to further extend the tools and knowledge within its existing domain. Symmetrical restrictions apply to small molecule scientists. Reversing the trends, in other works, to a considerable extent brings either team of scientists into "foreign territory". Nevertheless this reversal, we learn from HYP 2, is the general research strategy pursued by all firms, indicating this as the direction required to build value and to attract further venture capital. Not only is that indication substantiated by the verification of HYP 3. At the same time it is ascertained that firms individually are differentially valuated by venture capital precisely based on how far they get in strategizing their research to achieve this reversal.

Are these patterns established as general trends from the verification of HYP 1-2-3- also recognizable in closer inspections of specific firms? Appendix A profiles representative DBFs belonging to the most successful biotech start-ups in Denmark, one for each of the two discovery approaches.

\footnotetext{
${ }^{6}$ These findings should not be interpreted as saying that the emphasis on building knowledge in small molecule firms means that managers and investors in these firms are less concerned with pushing drug candidates through the pipeline towards commercialisation, instead pursuing scientific insight for its own sake. Rather the increasing KH/TS ratio reflects their interest in moving the right drug candidates through the pipeline. Alarmingly high failure rates prevail for drug candidates that have moved from discovery into the vastly more expensive stages of clinical testing, and this risk is particularly pronounced for small molecule candidates. The only effective way of avoiding losses of that magnitude is to validate drug candidates and their targets as thoroughly as possible, and that would be reflected precisely in the increasing KH/TS ratio observed for small molecule DBFs.
} 
The objective is to bring out what the knowledge assets and the trends, stylised and simplified in our three hypotheses, look like when observed in actual firms.

\section{Discussion and conclusions}

Together the verification of HYP 1-2-3 confirm research strategizing as an important aspect of the way biotech research firms are established and managed through their first years of existence. This paper has confirmed the role of research strategizing by demonstrating:

- Knowledge assets were shown to be shaped with distinct differences between two different approaches to drug discovery as part of the early activities of the firm. We refer to this shaping as strategising in the sense that knowledge architectures built by firms as part of their initial rounds of problem solving may be rationalised in Simonean fashion as responses to the architectures of the problems they address.

- Firms emerge as strategizers also in the sense that inventions, subsequent to the initial composition of knowledge architectures, reveal a systematic pattern of reversing the balance of problem solving and knowledge creation established initially. While this shift to some extent directs firms into "foreign territory", it is required to extract further commercial value from their initial investment in knowledge assets.

- This gradual rebalancing of the knowledge architecture, carried out over a sequence of inventions, represent a major challenge in research strategizing, and firms vary significantly in their ability to meet this challenge. Strategising precisely in this respect significantly affects evaluation of firms, and hence their ability to attract further venture capital at attractive rates.

Furthermore the analysis brought out that research strategizing refers to interactions between multiple distinct dimensions. DBFs are not valuated by any single attribute. Very little happens when firm valuations are regressed against our key independents variables individually. As singular attributes of biotech research, most of these dimensions contribute to successes in some firms and to failures in others. What matters for successful strategizing is the ability of firms to craft research strategies that are responsive to the particular opportunities and restraints of their core research competencies. This crafting requires multiple strategy dimensions to be carefully combined before they beneficially affect firm valuations.

In this sense, Shonhoovens argument that "strategy matters" has been shown to be valid not only for the larger high-tech firms covered by her study, but also for small research-based firms operating at the very well springs of knowledge where science directly interacts with technologies. Even though a lot more research is needed along these lines, the finding that strategy matters offers new implications for the understanding, management, and financing of these firms. Advise on how to run biotech start-ups often amounts to recommendations on "getting the right people" for their management and boards, but few attempts have been made to specify what it is the right people do in terms of setting directions for research. And the specialised business press on biotechnology is of little help in this context, not only because it so frequently redefines potential sources of success or risk for the sector, but also because it tends to consider them separately. This paper suggests the usefulness of further unpacking the contribution to their performance coming from multi-dimensional strategizing.

At the same time, the specific dimensions used for analysing research strategies in this paper should not incautiously be generalised and extended. While research strategizing as such may be expected to matter for small research-based firms also in other fields (e.g. nano-technology), these strategies 
most likely focus on dimensions different from those identified in this paper, reflecting the particular problem architectures of their domains. At the same time, the general Simonian approach applied in this paper, along with some of metrics developed for measuring knowledge and performance attributes, could be applied also in other technology fields.

Similarly, caution should be taken in generalising beyond the start-up stage of biotech firms the specific findings of this paper which has studied primarily quite small DBFs in their early years of existence. The main concern of start-ups is to stabilise and strengthen the inventions or concepts on which they were founded. That pursuit takes them in different directions depending on the type of discovery field they are operating in, but these directions reflect the common concern on nurturing the original knowledge assets of the company. As these pursuits succeed, firms will begin to formulate new concepts and inventions that may be continuous or diverging from their focus during their years as start-ups. Thus firms will cumulate knowledge developed for much more heterogeneous objectives, no longer lending itself to the type of interpretation by which research strategizing has been deciphered in this paper.

\section{Appendix A: Cases exemplifying differences in research strategies in two Discovery Fields}

Using publicly available sources only (company websites, patents etc.) this section presents two short cases on research strategies in DBFs, one working within a small molecule approach - 7TM Pharma A/S - the other being the biopharmaceurical firm of Bavararian Nordic A/S.

\subsection{TM-Pharma $A / S^{7}$}

Formed in 2000 as a spin-out from the University of Copenhagen in 2000, 7TM Pharma focuses on structure-based drug discovery of small molecules affecting 7TM receptors. The company's platform for research on the structure and function of 7TM receptors has given rise to a pipeline of drug discovery projects focusing on metabolic disorders. This particular type of receptor is present in multiple cell types within the human body, thus affecting a large number of functions of the human system, depending on which of the many different intra-cellular functions it activates.

7TM's Pharma has innovated and further developed a screening method, as well as a target validation method based on a novel test animal model. Together these two inventions - protected by seven patents - form a research platform capable of offering significantly enhanced effectiveness to multiple, targeted pursuits of drug discovery. In turn these research tools largely built on the science advanced though the 1990s by its founder, Professor Thue W. Schwartz of Copenhagen University.

The screening method offers a molecular approach for rapidly and selectively identifying small lead molecules capable of interacting with and binding to selected targets (Elling et al., 2001). Targets and leads subjected to screening by this method are modified so as to artificially bind and indicate their pattern of interaction

Based on this screening method 7TM has developed internal libraries containing both modified targets and modified leads. The modification confers on leads and targets in these libraries a set of properties that "natural" target proteins do not possess, and which are important for lead-target interaction. These properties in turn allow screening procedures to identify the degree of interaction between targets and leads in terms of signal strengths. This screening technology makes pattern

\footnotetext{
${ }^{7}$ The authors acknowledge contribution made to this case analysis from Martin Gürtler.
} 
recognition in large data volumes vastly more efficient, and for 7TM it has the particular value of being applicable to the entire 7TM receptor family.

Application of its screening tools has supplied the company with additional unique knowledge assets in the form of information on sub-types of 7TM receptors in terms of their inter- and intracellular functions along with their abilities to bind optimally and to interact with a lead compound. This information has been assembled on a limited number of 7TM receptors only. By homological reasoning, however, they greatly enhance formulation of hypotheses, search and interpretation regarding the identification of other 7TM receptors likely to hold the two essential properties of functionality and binding abilities. Homology allows information patterns to operate as search tools in new pools of data to identify potentially relevant areas in the 7TM receptor family.

The second invention from 7TM Pharma relates to a target validation method for testing the physiological importance, and therapeutic and pharmacological features of the drug-target interaction. The method makes it possible to genetically modify animals to express the desired properties in a potential drug target. When a test animal has been developed, the target may be turned on/off 'in vivo' experimentation, offering more precise indications of the validated targets' therapeutic and pharmacological features. In also allows for testing of the 7TM's proprietary target libraries in vivo with and without the modified feature as a basis for further improvement of target validation.

\subsection{Bavarian Nordic A/S}

Founded in 1994 and listed on the Danish Stock Exchange since 1998, the biopharmaceutical DBF of Bavarian Nordic today has research and manufacturing activities in Denmark, Germany and California. Bavarian's technology platform comprises MVA-BN vaccine technology and a number of vaccine technologies for infectious diseases related to smallpox, such as HIV and flavi viruses. In addition to traditional targets for vaccine technology, Bavarian Nordic has also ongoing research on vaccine treatments of cancer.

The MVA-BN platform is based on the Modified accinia Ankara (MVA). It builds on efforts to reduce negative side effects of ordinary smallpox vaccines, which in the early 1960 resulted in the development of MVA offering safe vaccination even for immune compromised individuals. Modifications of the MVA were achieved by passing it through hundreds of chicken embryo fibroblast cell generations. Through this process, the MVA lost approximately $10 \%$ of its genome and, as a consequence, its ability to replicate efficiently in primate cells, allowing it to become the cornerstone of a potential smallpox vaccine.

The modern genetically modified version of the MVA, denoted MVA-BN, induces a high antibody and cellular immune response, making it effective for treatment of several types of infections, without negative side effects. The MVA-BN differs from the original MVA in the two crucial respects of 1) allowing the integration of foreign DNA into its genome and 2) reducing the potential number of cells hosting and enabling replication of viruses. MVA-BN generates a strong immune response by neutralising antibodies and cytotoxic T-cells (CTL). The response is directed towards both MVA and foreign DNA cloned into MVA-BN.

Bavarian's research on MVA-BN platform was initiated in 1995. Projects have focused on improved construction of stable recombinant vaccines within the original target of smallpox. But its unique control of specific cascades in the immune system also allows the company to address new diseases. Some vaccines are, for instance, fitted with multiple genes of high homology. The latter is important for the development of multivalent vaccines targeting, for instance, HIV and dengue fever. 
Bavarian Nordic is involved in HIV vaccine research through a collaboration agreement with the US based biotech firm Epimmune Inc. Recent research has showed evidence of effective CTL response, which is required to protect against HIV and hamper development of AIDS. Since MVABN platform exhibits those characteristics, Bavarian Nordic believes that the MVA-BN technology combined with Epimmune's technology in related fields of T-cell epitope identification may develop such a vaccine.

Bavarian Nordic also conducts research in other infections diseases, primarily oriented towards illnesses caused by viruses of the flavi family type. This includes research in vaccines for dengue fever, Japanese Encephalitis Virus, Hepatitis C Virus and West Nile Virus. The benefits of the MVABN platform allows Bavarian Nordic to utilise the ability of MVA vehicles to deliver, for instance, multiple antigens for all four serotype of the dengue fever virus. This vaccine may induce broad cross-strain immunity against dengue and become a first-mover in the market. 


\section{Reference List}

Barney, J. B. (1986) 'Types of Competition and the Theory of Strategy: Toward an Integrative Framework', Academy of Management Review, 11(4), 791-800.

Breschi, S., F. Lissoni and F. Malerba (2003) 'Knowledge-relatedness in firm technological diversification', Research Policy, 32(1), 69-87.

Casper, Steven, Anastasios Karamanos, and Fiona Murray (2002), Coupling and Decoupling from the Science Base. Determinants of Start-up Strategies for Accumulating Scientific Knowledge,

Chandler, Alfred D. (2005), Shaping the Industrial Century: The Remarkable Story of the Evolution of the Modern Chemical and Pharmaceutical Industries, Boston, Mass: Harvard University Press .

Chataway, J. and J. Tait (1993) 'Management of Agriculture-related Biotechnology: Constraints on Innovation', Technology Analysis \& Strategic Management, 5(4), 345-367.

Cockburn, I., R. M. Henderson and S. Stern (2001) 'Untangling the origins of competitive advantage', Strategic Management Journal, 21(10-11), 1123-1145.

Dahlgren,H., Jensen,R.L., and Valentin,F., 2004, "Heterogeneity of Intellectual Assets - A Method for Identification and Measurement With Patent Data". Research Centre on Biotech Business, Biotech Business Working Paper

Dierickx, I. and K. Cool (1989) 'Asset Stock Accumulation and Sustainability of Competitive Advantage', Management Science, 35(12), 1504-1511.

Dimasi, J. A., H. G. Grabowski and J. Vernon (1995) 'R\&D Costs, Innovative Output and Firm Size in the Pharmaceutical Industry', International Journal of Economics of Business, 2(2), 201-219.

Drews, J. (2000) 'Drug Discovery: A Historical Perspective', Science, 287, 1960-1964.

Drews, J. (2003) 'Stretegic trends in drug discovery', Drug Discovery Today, 8(9), 411-420.

Fazeli, S. (2005) 'The European biotech sector: Could it achieve more?', Journal of Commercial Biotechnology, 12(1), 10-19.

Gilsing, V. and B. Nooteboom (2006) 'Exploration and exploitation in innovation systems: The case of pharmaceutical biotechnology', Research Policy, 35(1), 1-23.

Guedj,I. and Scharfstein,D., 2004, "Organizational Scope and Investment: Evidence from the Drug Development Strategies and Performance of Biopharmaceutical Fims". NBER, NBER Working Paper

Jaffe, A. B. (1986) 'Technological Opportunity and Spillovers of R\&D: Evidence from Firms' Patents, Profits, and Market Value', American Economic Review, 76(3), 984-1001.

Jaffe, A. B. (1989) 'Characterizing the "technological position" of firms, with application to quantifying technological opportunity and research spillovers', Research Policy, 18(2), 87-97.

Jorgensen, W. L. (2004) 'The Many Roles of Computation in Drug Discovery', Science, 303(5665), 1813-1818.

Klahr, David (2000), 'Scientific Discovery as Problem Solving', Exploring Science. The cognition of Development of Discovery Processes, Cambridge, Mass.: The MIT Press,

Langlois, Richard N. (1999), 'Scale, Scope and the Reuse of Knowledge', in Sheila C. Dow and Peter E. Earl (eds), Economic Organization and Economic Knowledge, Cheltenham: Edward Elgar, pp. 239-254.

Lerner, J. (1994) 'The Importance of Patent Scope: An Empirical Analysis', RAND Journal of Economics, 25(2), 319333.

Liebeskind, J. P., A. L. Oliver, L. G. Zucker and M. B. Brewer (1996) 'Social networks, learning and flexibility: sourcing scientific knowledge in new biotechnology firms', Organization Science, 7(4), 428-443.

Lynskey, M. J. (2006) 'Editorial: a strategy to optimise the business value of Intellectual Property', International Journal of Biotechnology, 8(3-4), 146-168.

Murray, F. (2002) 'Innovation as co-evolution of scientific and technological networks: exploring tissue engineering', Research Policy, 31(8-9), 1389-1403. 
Nightingale, P. (2000) 'Economies of Scale in Experimentation: Knowledge and Technology in Pharmaceutical R\&D', Industrial and Corporate Change, 9(2), 315-359.

Nilsson, A. (2005) 'The process of value building in science-based companies: Geron and the \&\#39;Telome-race\&\#39', International Journal of Biotechnology, 7(4), 288-306.

Nilsson, A. (2006) 'The race for pace: inhibitors and accelerators - developing the first product in new science-based companies', International Journal of Biotechnology, 8(3-4), 225-2.

Owen, Geoffrey (2004), 'Where are the big gorillas? High technology entrepreneurship in the IK and the role of public policy', The Diebold Project UK.

Peteraf, M. A. (1993) 'The Cornerstones of Competitive Advantage: A Resource-Based View', Strategic Management Journal, 14, 179-191.

Porter, Michael E. (1980), Competitive strategy -techniques for analyzing industries and competitors, New York: Free Press.

Powell, W. W., K. W. Koput and L. Smith-Doerr (1996) 'Interorganizational collaboration and the locus of innovation: Networks of learning in biotechnology', Administrative Science Quarterly, 41(1), 116-145.

Re-Jin Guo, B. Lev and Nan Zhou (2005) 'The Valuation of Biotech IPOs', Journal of Accounting, Auditing \& Finance, 20(4), 423-259.

Rothman, H. and A. Kraft (2006) 'Downstream and into deep biology: Evolving business models in 'top tier' genomics companies', Journal of Commercial Biotechnology, 12(2), 86-97.

Scherer, F. M. (1982) 'Interindustry Technology Flows in the United States', Research Policy, 11, 227-245.

Schmid, E. F. and D. A. Smith (2004) 'Is pharmaceutical R\&D just a game of chance or can strategy make a difference', Drug Discovery Today, 9(1), 18-26.

Schoonhoven, C. B. (1984) 'High technology firms: Where strategy really pays off', Columbia Journal of World Business, 14(Winter, 4), 5-16.

Schoonhoven, C. B., K. M. Eisenhardt and K. Lyman (1990) 'Speeding Products to Market: Waiting Time to First Product Introduction in New Firms', Administrative Science Quarterly, 35(1), 177-207.

Shapiro, Carl (2001), 'Navigating the Patent Thicket: Cross Licenses, Patent Pools, and Standard-Setting', in Adam B. Jaffe, Joseph Lerner and Scott Stern (eds), Innovation Policy and Economy, Volume I, Cambridge, Mass: MIT Press,

Simon, Herbert A. (1969), The Sciences of the Artificial, Cambridge, Mass.: The MIT Press.

Teece, D. and G. P. Pisano (1994) 'The Dynamic Capabilities of Firms: an Introduction', Industrial and Corporate Change, 3,(3,), 537-556.

van Raan, A. F. J. and E. C. Engelsman (1993) 'International Comparison of Technological Activities and Specializations: A Patent-based Monitoring System', Technology Analysis \& Strategic Management, 5(2), 113-137.

Verspagen, B. (1997) 'Measuring Inter-sectoral Technology Spillovers: Estimates from the European and US Patent Office Databases', Economic Systems Research, 9(1), 49-67.

Wernerfelt, B. (1984) 'A Resource-based View of the Firm', Strategic Management Journal, 5, 171-180.

Zucker, L. G., M. R. Darby and J. S. Armstrong (2002) 'Commercializing knowledge: University science, knowledge capture, and firm performance in biotechnology', Management Science, 48(1), 138-153. 